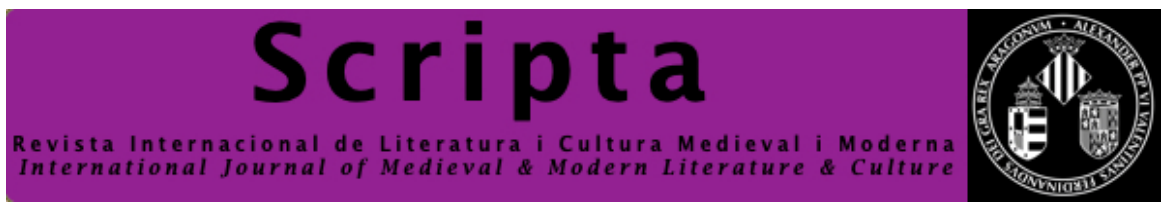

\title{
Les fonts clàssiques de Curial e Güelfa
}

\author{
The classical sources of Curial e Güelfa
}

\author{
ABEL SOLER \\ abel.soler@uv.es \\ Universitat de València
}

\begin{abstract}
Resum: Curial e Güelfa (Milà-Nàpols, ca. 1445-1448), novel la cavalleresca escrita en català i atribuïble al gran camarlenc del Nàpols d'Alfons el Magnànim, Enyego d'Àvalos, conté una suggerent càrrega culturalista (mites ovidians tergiversats satíricament; teofanies i decorats neoplatònics; remissions explícites i/o implícites Cèsar, Macrobi, Plató, Apuleu...), que no resulta en absolut supèrflua i prescindible, com argumentà algun crític del segle passat. Al contrari: la manera d'evocar-hi els clàssics i de re-presentar-los no s'explica sense considerar els contactes de l'hipotètic escriptor amb l'humanisme llombard i napolità. D'altra banda, el repertori de clàssics greco-llatins documentats en la variada biblioteca personal del mateix D'Àvalos, la segona més rica del sud d'Itàlia, evidencia la coincidència de gustos i lectures d'aquest amb l'anònim del Curial i convida a ratificar la referida atribució.
\end{abstract}

Paraules clau: Curial e Güelfa, Enyego d'Àvalos, literatura catalana medieval, novel la cavalleresca, cavalleria humanística.

Abstract: Curial e Güelfa (Milan-Naples, ca. 1445-1448), a chivalric romance written in Catalan an attributable to the great chamberlain in the Naples of Alfonso the Magnanimous, Enyego/Inico d'Àvalos, contains a suggestive cultural burden (Ovid's myths satirically distorted; theophanies and Neo-platonic sets; explicit and/or implicit references to Caesar, Macrobius, Plato, Apuleius...), which is not absolutely superfluous nor dispensable, as some critic from the last century explained. Just the opposite: the way to recall the classics and re-present them cannot be explained without considering the contacts of the hypothetical writer with the Lombard and Neapolitan Humanism. On the other hand, the catalogue of Greek-Latin classics recorded in the varied personal library of D'Àvalos himself, the second richest in the south of Italy, demonstrates the coincidence of his taste and readings with the anonymous writer of the Curial and invites us to ratify the aforementioned attribution.

Keywords: Curial e Güelfa, Enyego d’Àvalos, medieval catalan literature, chivalric romance, humanistic chivalry.

\footnotetext{
* Aquest article és una comunicació llegida en la «Jornada sobre la presència dels clàssics en la Romània durant l’edat mitjana (València, 17 de novembre 2017)», celebrada a la Facultat de Filologia, Traducció i Comunicació de la Universitat de València, sota la direcció i coordinació del Prof. Emili Casanova. El text està pensat com una síntesi divulgativa d'aportacions tractades amb major complexitat i profunditat -i amb un extens aparell erudit- en Soler (2017b : II, 1028-1590).
} 


\section{Introducció.}

La crítica literària del segle passat no encertava a interpretar l'afany de l'autor del Curial -un personatge anònim; brillant, però enigmàtic- per mostrar-se davant els seus oients com un lector erudit i format en matèria clàssica. Ho consideraven un simple afany de participar de la moda d'ornar artificiosament les obres de lluïment literari amb històries mitològiques apreses d'enciclopèdies i de mitògrafs a l'ús. Hi havia fins i tot algun crític que considerava la trama mitològica del Curial una part «prescindible», postissa, perquè destorbava la fluïda comprensió d'una trama argumental de cavalleries i amors. Pesava sobre la interpretació de la novel la l'apreciació de considerar-la un mélange original, una estranya combinació d'edat mitjana i Renaixement, com deia Milà i Fontanals.

A partir de la dècada del 1980, tanmateix, estudiosos del Curial com Lola Badia, Júlia Butinyà, Xavier Gómez Font, Jaume Torró i Sònia Gros, entre d'altres, han posat en evidència que els components mitològics i erudits de Curial e Güelfa constitueixen una part d'imprescindible d'anàlisi i de consideració interpretativa per als qui aspirem a assolir una correcta comprensió de les intencions literàries de l'autor. A més, s'ha vist com la plasmació literària de la matèria clàssica en la novel la connecta significativament amb la ficció cavalleresca traçada en paral lel, sense alterar-ne la voluntat de versemblança. Els clàssics, en el Curial, constitueixen un material de recerca i d'anàlisi ineludible, doncs. I, segons el que hem pogut comprovar, s'hi ofereixen també com un material sorprenent... D'altra banda, és clar que el tractament de les fonts literàries de l'obra en general, i de les clàssiques en particular, ajuda l'estudiós a perfilar el retrat de l'escriptor i, lògicament, a reconstruir la seua «biblioteca mental»: els llibres que preferia consultar i llegir, o les fonts erudites d'on poava les «poètiques ficcions», com ell les denomina.

En la nostra tesi doctoral, llegida a València l'any 2016, rellegírem i replegàrem tot el que s'havia escrit i discernit amb anterioritat sobre les fonts literàries i sobre els referents culturals de la novel la anònima. No obstant això, i per a sorpresa nostra, encara vam poder multiplicar el corpus de referències i d'intertextualitats amb autors de l'Antiguitat clàssica, en un apartat que ocupa centenars de pàgines (Soler 2017b: II, 1028-1590). El tractarem de compendiar ací a manera de quadre sinòptic. La nostra intenció, amb aquest article, és la d'ajudar a divulgar la riquesa d'informació cultural que, sobre el palimpsest d'una temàtica medieval -cavalleries i enyorances trobadoresques-, introduí de manera discrecional un escriptor, l'autor del Curial, que nosaltres identifiquem amb el gran camarlenc de la cort napolitana d'Alfons el Magnànim, el cavaller Enyego d'Àvalos (Soler 2017a i 2018). Com més avall es comprovarà, el repertori de fonts i de lectures de l'autor del Curial encaixa a la perfecció amb els gustos literaris i amb la selecta biblioteca del culte cortesà, i constitueix, de fet, una de les proves més eloqüents que permeten d'atribuir-li l'obra.

Algunes d'aquestes fonts clàssiques són directament consultades per l'escriptor; d'altres, foren indirectament citades $\mathrm{o}$, fins i tot, conegudes per l'autor «per fama». Es comprova fàcilment, en qualsevol cas, que som al davant d'un escriptor avesat a l'estudi de commenti de la Divina Comèdia, de glossaris com els de Pàpias, i de repertoris mitogràfics com les Genealogie deorum gentilium de Boccaccio. Aquesta constatació fa que el resultat de la recerca ens porte a definir l'autor d'una 
manera menys desdibuixada que en aproximacions anteriors d'altres estudiosos. Per exemple, quan Antoni Ferrando edità Curial e Güelfa, comentà que l'anònim «va extraure de lectures, no sempre ben païdes, d'obres i glosses de clàssics llatins, com Ciceró, Sal lusti o Valeri Màxim, de pares de l'Església, com Gregori el Gran o Pròsper d'Aquitània, i de coneguts escriptors llatins d'època medieval, com Fulgenci o Pàpies» (2007: 10). A l'any següent, el 2008, en un simposi celebrat a París, el llatinista Juan Francisco Mesa Sanz comprovà que, en realitat, moltes d'aquelles cites procedents -en teoria- de Ciceró, Valeri, Gregori, Pròsper, etc., provenien de fonts de segona mà, de repertoris italians (constatació certificada per ell mateix en Mesa Sanz 2012). L'escriptor les havia preses, fonamentalment, de commenti de la Comèdia de Dante, com els de Benvenuto da Imola i Pietro Alighieri. Nosaltres, per la nostra banda, hem pogut certificar que aquest Da Imola esdevingué el vademècum predilecte de l'autor, del qual prengué més de cinquanta notes, útils per a l'ornament erudit del Curial.

Com s'observa, la comunicació de Mesa Sanz -on connectava els gustos lectors de l'autor amb els dels cenacles humanístics italians- no es publicà fins el 2012. Potser per aquesta raó, en l'edició del Curial anotada críticament per Lola Badia i Jaume Torró figurava encara un retrat molt medieval de l'anònim, a través de les fonts: «Pel que fa als materials patrístics i escolàstics, trobem esmentats el noms de sant Jeroni, Pròsper d'Aquitània i Joan de Llemotges, al costat de les citacions corresponents, però també hi ha materials presos de sant Agustí, sant Gregori i sant Isidor...» (2011: 59). No hi trobaven cap explicació, d’altra banda, les presumptes «incongruències» i els «pintoresquismes» que, segons la professora Lola Badia (1988 [1985]: 175) caracteritzaven els gustos erudits de l'anònim. En un altre treball del 1987, es referia a «pistes falses» (8, n. 15). En l'edició del 2011, després de molts anys d'intentar explicar-les, havien assolit ja el grau de «perplexitats» (9).

Òbviament, el fet de voler fer encaixar-com en un llit de Procust- el context creatiu del Curial e Güelfa a la Catalunya conflictiva i perifèrica de mitjan segle XV -malgrat les preferències lèxiques valencianes de l'obra- o «en les corts ibèriques dels Trastàmara», com llegim en articles de Badia i Torró dels anys 2010-2015 -malgrat la palmària italianitat de l'obra en fonts i múltiples aspectesdistorsiona la correcta interpretació de l'obra i genera «perplexitat». Per no parlar ja d'especulacions com la de Jaume Riera i Sans, o la de la catedràtica de literatura espanyola Rosa Navarro Duran (encara en articles del 2016 i 2017), que propugnaven la falsedat de l'obra per trobar-la inexplicablement moderna.

No cal insistir-hi: paleògrafs, historiadors i lingüistes, i la crítica literària en general, han certificat l'autenticitat de l'obra. Encara que pocs han pogut explicar, de la manera que ho mostrem nosaltres, com i per què l'autor es riu dels lectors del Doctrinal de Pacs, un opuscle sapiencial que circulava per la cort napolitana, i transforma satíricament una frase misògina d'aquest doctrinal en una cita de Plató. O per què fa broma amb la visita de Curial a uns inexistents sepulcres d'Etèocles i Polinices; quan tothom que haguera llegit la Tebaida d'Estaci recordaria el genial passatge del combat de les flames d'ambdós cadàvers sobre la pira funerària on foren incinerats... En realitat, 
tot el Curial, i especialment algun capítol dens, com és el III.15, està farcit de facècies culturalistes i tergiversacions en clau paròdica de fonts clàssiques. Tot això es combina amb altres bromes de caire polític, o referides a ressons diplomàtics i autobiogràfics d'Enyego d'Àvalos. El primer aspecte, el de l'erudició sotmesa a la sàtira, s'entén bé en un autor relacionat amb els cenacles humanístics d'Itàlia; encara que, lògicament, desconcertava els experts en literatura catalana medieval pel 1985. Per què? Doncs, fàcilment: perquè el Curial és un llibre escrit en català, indiscutiblement, però que té més d'humanístic que de medieval, i molt més d'italià que d'ibèric.

El desconcert, encara vigent, de Lola Badia només li feia acceptar «dues maneres de jutjar aquestes incongruències i aquests pintoresquismes» de l'anònim autor. Notem que no escriu interpretar, sinó jutjar: o bé l'autor altera la matèria clàssica per a dotar algun passatge «d'un cert aire esotèric», «O més brutalment», hem de «pensar que la ignorància del nostre anònim no dóna per a més. Creure que fonamentalment la manera correcta de jutjar-les és la segona, no implica necessàriament desestimar la primera» (1988 [1985]: 175). Després del que hem pogut verificar al llarg d'anys de recerca, hem comprovat que l'ocurrència de tractar l'escriptor d'ignorant o d'esotèric derivava de la pretensió apriorística -implícita en el judici de Badia- de fer-lo encaixar en un ambient ibèric, medievalitzant.

La perplexitat de la crítica literària del segle passat deixa de tenir sentit quan s'admet -a partir de les proves que més avall s'ofereixen- que l'autor del Curial és algú bastant diferent, des del punt de vista formatiu i intel lectual, a un cavaller ibèric o medieval, com podia ser Martorell. Hauríem d'admetre que és algú que coneix un nombre interessant d'obres clàssiques i que practica una imitatio humanística. És algú que no plagia literalment els autors que llig, sinó que els adapta per a camuflar citacions. Però és que, a més, es veu amb suficient autoritat i capacitat per a representar satíricament aquesta matèria clàssica. Participa d’una manera de veure el món que ja no és estrictament medieval, sinó humanística. Fa la sensació que parlem d'algú que escriu a Itàlia i en contacte amb cenacles humanístics. Aquesta sensació augmenta de grau quan comprovem que l'escriptor tenia coneixement de La República de Plató o de l'Ase d'or d'Apuleu, de difícil accés fins i tot a Itàlia.

L'enfocament interpretatiu de Curial e Güelfa va canviar radicalment quan, després de procedir a una caracterització prosopogràfica i cultural de tots els personatges de la cort napolitana d'Alfons el Magnànim relacionables amb les lletres -una tasca increiblement pendent (Soler 2017b: I)-, no detectàrem, com prevéiem, diversos candidats a atribució d'autoria. Només poguérem comprovar que un únic i brillant cortesà, Enyego d’Àvalos, lector empedreït i posseïdor de la segona biblioteca més rica del sud d'Itàlia per darrere de la col lecció reial, podia ser proposat com l'autor de Curial e Güelfa; per múltiples raons, proves i indicis, que sintetitzem i exposem en Soler (2018). Només cal repassar l'inventari de la secció humanística de la biblioteca davaliana, és a dir, de la part heretada per la seua culta filla Constança (De Vivo), per a veure com es verifica una eloqüent correlació entre els interessos lectors del gran camarlenc en matèria clàssica i els de l'anònim redactor del Curial. La circumstància convida, entre moltes altres que seria llarg d'exposar, a identificar-lo, sense cap 
alternativa versemblant a la vista, com l'autor de la novel la. Ultra a això, les reiterades referències a D'Àvalos com a justador expert, culte lector de literatura, amic d'humanistes i redactor elegant, en fonts coetànies, contrasten amb la mancança de dades similars al respecte al seu entorn: ni en la seua família o cercle d'amistats, ni en la resta de cortesans d'una cort on l'expressió literària en romanç fou relativament mediocre.

En realitat, i a diferència del Tirant lo Blanc, escrit per Martorell per al gaudi de «la nació» d'on era natural, Curial e Güelfa -un text del qual només es coneix només una còpia manuscrita- té tot l'aspecte de ser una obra literària molt personal, i àdhuc confidencial en alguns aspectes anecdòtics. Està plena de ressons i de bromes autobiogràfiques, únicament comprensibles si els oients davant els quals es preveia recitar l'obra (en un horitzó de recepció sembla que restringit a la cort de Nàpols, com certificava la medievalista Maria Teresa Ferrer i Mallol 2011) estaven una mica al corrent, si més no, de la vida i dels gustos literaris de l'autor. Podríem parlar de referències onomàstiques, heràldiques, lexicogràfiques i d'altra mena, contingudes en Curial e Güelfa, que connecten amb la trajectòria biogràfica del valencià d'adopció que fou Enyego d'Àvalos. Criat en infantesa i joventut a la cort de València, Enyego es formà literàriament a les corts de Milà i de Nàpols, en un ambient humanístic, i fou després un gran mecenes dels millors humanistes d'Itàlia. Tanmateix, lluny de perdre'ns en altres constatacions (que trobareu més adequadament exposades en Soler 2018), ens centrarem ara i ací en repassar succintament les connexions que presenta la novel la cavalleresca amb algunes obres i autors de l'Antiguitat grecollatina.

Cal advertir d'entrada, però, que aquestes fonts clàssiques del Curial e Güelfa, en múltiples casos, hi apareixen filtrades o matisades en algun detall per la consulta en paral lel de les Genealogie deorum gentilium de Giovanni Boccaccio, o dels commenti dantescos de Benvenuto da Imola i Pietro Alighieri. Significa que l'escriptor, que era home estudiós i filòleg amateur, però no humanista pròpiament dit, necessitava auxiliar-se d'exposicions i repertoris que l'ajudaren a entendre millor els continguts mitològics, tan de moda en el Quattrocento. També hi ha algun deute anecdòtic amb Enric de Villena, per exemple.

Aquest recurs a les fonts clàssiques de segona mà no sorprén tant, tanmateix, com l'evidència -per insospitats detalls d'erudició exhibida- que es tractava d'algú amb estrets contactes amb l'humanisme llombard -amb Francesco Filelfo i els germans Decembrio- i amb l'humanisme napolità, per ser amic i afavoridor d'Antonio Beccadelli i Lorenzo Valla. El mateix Filelfo, en el primer dels Convivia Mediolanensia (1443), presenta un Aenicus Davalus que disserta sobre temes clàssics coincidents amb els del Curial. D'altra banda, observem que l'escriptor degué consultar algun Ovidi moralitzat milanés. Per a documentar la vida de Plató, tingué present una obra molt divulgada a Milà, el Pseudo-Burley, que trobem encara hui a Catània amb l'ex-libris de D'Àvalos. Si afegim a aquestes evidències la consulta pel redactor del Curial d'altres manuscrits milanesos i montferratesos únics, de temàtica enciclopèdica i cavalleresca, se'ns presenta D'Àvalos, diplomàtic i lletraferit resident durant molts anys a Milà, com el més que probable autor del Curial e Güelfa. Si el redactor del Curial, 
qüestió apuntada des de fa temps per la crítica, disposava d'una bona biblioteca de clàssics a l'abast, aquesta sembla que no era tant la biblioteca reial napolitana d'Alfons el Magnànim -com podríem haver plantejat hipotèticament, d'entrada-, sinó la seua pròpia biblioteca, una biblioteca davaliana, relativament desconeguda i poc estudiada. ${ }^{1}$

\section{Fonts clàssiques documentades en el Curial}

\section{Literatura patrística}

1. LACTANCI. Hi ha còdex davalià del 1430 (obtingut el 1440 a Milà i conservat a Viena). * Institutiones divinae, I, XVII, 9-11 // I, 11: Sàtira de Venus com a «dea de luxúria e puteria» (CeG III.23). ${ }^{2}$ // Els poetes, en «fingir», no menteixen.

2. PSEUdo-Tertulì (Anònim del segle IV). Manuscrits existents a Nàpols i a Milà. * Passio Sanctarum Perpetua et Felicitatis, I, 1; IV, 9-10; XX, 2-5, i XXI, 9-10: La vida i martiri de Perpètua de Cartago per a caracteritzar paròdicament Càmar de Tunis (CeG III.48-68).

3. Agustí. D’Àvalos posseïa diversos volums seus, entre ells uns Opuscula. * Enarrationes in Psalmos, In psalmo LXXXIII, 9, vers. 6-7: Melcior de Pando i la «pesada e anciana carn» (CeG II.142). Expressió compartida amb Carles de Viana. * De vera relgione, XXXIX, 72: Admonició de Melcior a Curial: «que torns en tu mateix, regoneix-te bé» (CeG II.144). * De Civitate Dei, I, xv, 2: En l'home virtuós, «la captivitat no tol la virtut», segons l'exemple de Marc Atili Règul ( $C e G$ III.55). Es conserva a Londres un còdex davalià (de ca. 1445) d'aquesta obra. * Sermones, XCIX, 6: Concepte teològic de «gràcia prevenint» o gratia praeveniens (CeG III.2), segurament apresa de Pietro Lombardo, Sententiae, 11. II, distinc. XXVI, cap. 1, 162. L'obra de Lombardo era present en la biblioteca davaliana.

4. Jeroni. Autor present en la biblioteca davaliana, inclòs un volum amb les Epistolae. * Adversus Iovinianum: Opuscle citat satíricament per Apol lo (CeG III.34) per a demostrar que la reina Dido era una vídua honesta i fou difamada per un Virgili «mentider». També coneix l'opinió de Petarca (Seniles, IV, 5, suggerit per Jaume Torró) i Da Imola (Purg. XXXI, 43-48). * Epistola ad Paulinum (Epistolae, III, LIII), 1: Plató, presoner i esclau d'un tirà, demostra ser més lliure que el seu comprador (CeG III.55). La consulta depén en part d'una font intermèdia, el pseudo-Burley de D’Àvalos (Bca. Univ. de Catania), adés comentat. * Epistolae, III, LIV, 6: Proverbi de ressignació estoica: «fets de la necessitat virtut» (CeG II.6). Era conegut: apareix ja en Eiximenis i en la cancelleria reial $(1439,1460)$.

1 Encara que els seus còdexs, dispersos per biblioteques de mig món, han sigut objecte d'aproximacions puntuals o circumstancials, l'única visió de conjunt - precedent de la nostra- deriva de la publicació d'un inventari de la secció humanística del llegat d'Enyego a la mort de la seua filla Constaça (De Vivo 1996).

2 Citarem el text del Curial a partir de l'edició de Ferrando (2007), per ser la més acostada, en criteris de transcripció paleogràfica i de seguiment de la distribució original dels capítols continguda en el manuscrit. S'abreujarà el títol en sigles $(C e G)$, el llibre o part en numerals romans i el capítol en xifres aràbigues. 
5. Gregori el Gran. Autor citat explícitament, però en clau irònica i paròdica. D’Àvalos posseïa les obres de sant Gregori. * Epistolae, IX, 59: «Omnes secundum rationem humilitatis aequales sumus» (CeG III.0), amb Pietro Alighieri (Commentum, 3a red., Purg. IX, 67-69) d'intermediari, com adverteix Juan F. Mesa. * Index sententiarum memorabiliarum (PL 220, col. 745): «Vilescunt temporalia cum considerantur eterna» (CeG III.0), a través de Pietro Alighieri, també (Commentum, 1a red., Purg. IX, 79-93, i 3a, ibid., 79-142). * Diàlegs, I, 3-5: Sant Paulí de Nola presoner en un hort de Tunis, anècdota com la de Curial. El de Nola era patró dels Orsini-Del Balzo, la família política del duc de Calàbria, Ferran d'Aragó.

6. Pròsper d'Aquitània. Autor citat explícitament, en context paròdic. * Liber sententiarum, cap. 129 (De superbia): «Cum omnia vicia superaverit homo, manet periculum vehemens, cum consciencia pocius in se quam in Deo glorietur» (CeG III.0). Empra d'intermediari, segons Juan F. Mesa, Gulielmus Peraldus, Summa de virtutibus et vitiis (VI. De superbia, 39).

\section{Filòsofs, oradors i tractadistes antics}

1. Plató. Autor citat explícitament. Decembrio regalà a D’Àvalos un dels 10 primers exemplars de La República en llatí, com s'ha dit. * Rep. 451d-452a (V, II, 3-6): Facècia sobre el «seny» dels homes i la «bellesa» de les dones, citant el Doctrinal de Pacs, que contradiu Plató (CeG II.42). * ibid., 473cd: Ideal del rei literat i amic de filòsofs, en boca del rei de França ( $G e G$ II.116). Lectura directa, o a través de Boeci (Consolatio Philosophiae, I, IV, 5), o per la dedicatòria a D’Àvalos per Decembrio d'un llibre de Cèsar (1438). En La República de D’Àvalos (Biblioteca Vaticana), Decembrio crida d'atenció amb un «attende lector» en aquest passatge, que recorda el «legidor, atén bé» del Curial. * ibid., 614c-621d (el mite d'Er): El riu de Lete (CeG I.26); les Moires i Necessitat (CeG II.144); el nom de la «verge Làquesis» (elecció vici/virtut); la virtut «en mans de cascú» (CeG I.7); evitar els extrems (CeG II.88). * El Convit, 187c: L'harmonia entre els dos vessants de l'amor de Venus genera «concòrdia..., e convida les gents a amar-se» (CeG III.22). La Venus Urània deïficada i «celestial». Els humanistes llombards i florentins, i Lorenzo Valla, debatien sobre aquest assumpte en les dècades del 1430-1440. * ibid., 187a-188b: Venus amb la corona d'estels (els 100 ulls d'Argus, d'Ovidi, Metam. 720-721), per l'associació platònica d'harmonia celestial i harmonia amorosa. Guiniforte Barzizza aconsella a Francesc de Centelles (valencià, amic de D’Àvalos), que opte per un coelicus ignis amorós (Milà, Epistula de amore, 1439).

2. Aristòtil. Autor citat com «lo Philòsof». L’exemplar dels llibres Ethicorum de D'Àvalos (del 1440) es conserva a Londres. * Ėtica a Nicòmac, ll. IV, cap. 12 (1126b, 12-23 i 29-30, i 1127b, 8-10): Concepte de «vera e no popular amicícia» (amabilitat vs. adulació). * ibid., 1l. 1, cap. 10 (1101a): «En los infortunis prova hom la virtut de los hòmens» (CeG II.122). * ibid., 1l. 2, cap. 8 (1108d) i ll. 2, cap. 9 (1109a-b): La virtus in medio, la «temperància» i l'evitació dels extrems com a vector ètic $(C e G$ II.0, II.24, II.74, II.101, II.111, II.116 et passim). * Política, 1293b: Meritocràcia: Curial triomfa i esdevé 
príncep «per sos mèrits» (CeG II.86, III.89 i III.100). Leonardo Bruni envià a Nàpols, al rei Alfons, la versió llatina de la Política el 1441.

3. CiCERó. Autor present en la biblioteca davaliana. * De inventione, II, LV, 166: «Vana gloria est magni dicti et magni facti frequens fama cum laude» (CeG III.0). Com constata Juan F. Mesa, l'intermediari de la citació és Pietro Alighieri (Commentum, 1a red., Purg. XI, 79-93). * De natura deorum, II, 53: «[L'estrella Venus] és apellada en grech Júbar, que vol dir 'llum'». D’Àvalos posseïa el De natura deorum, d'on aprén l'eclecticisme i la suspensió de judici. * Somnium Scipionum: Vers la fi del llibre III, segons Júlia Butinyà, el Curial segueix el guió del comiat d'aquesta obra. Text accessible partir del Comentarium de Macrobi, al ludit en el Curial. Decembrio, en la dedicatòria d'un llibre de Cèsar a D’Àvalos, li recorda la recompensa del Somnium Scipionis. * Pro lege Manilia, XIII, 36: Curial, virtuós: «en moltes e en les més coses serva honesta temperància» (CeG II.0). Citat com «quanta in omnibus rebus temperantia» en una lletra dels Medici (Leonardo Bruni) a Carlo Malatesta (1429), rebuda per Decembrio, íntim amic de D’Àvalos a Milà i a Nàpols.

4. SÈnECA. D’Àvalos posseïa el De beneficiis i les Epistoles a Lucil li. El germà, Alfons, apareix en Beccadelli debatent sobre una d'aquestes epístoles en «l'hora del llibre». * Tragèdies (Medea, Oedipus, Hercules furens, Hyppolitus, Agamèmmnon). Diverses intertextualitats amb la versió catalana, accessible a València i a Nàpols. * De providentia, II, 10: Cató ensenya «lo camí de la llibertat» a Càmar (ed. del Curial de Lola Badia i Jaume Torró), partint de la traducció catalana d'Antoni Canals. * De brevitate vitae, I, 3 // VII, 1: «tenint per perdut aquell temps que sens studi havia viscut» (CeG III.79) // Caure en el vici és «errar» (CeG I.12, II.136, II.138, II. 145, III.9 i III.76). La primera frase, citada per Beccadelli en De dictis et factis Alphonsi regis. * Epistulae ad Lucilium, III, 51: El vici i la depravació com a «sepulcre» de l'home (CeG III.79). Divulgat per Petrarca, De vita solitaria, III, 354. * De beneficiis, III, II, 1 i III, 1 / / IV, vIII, 1-2: Discurs de Melchior sobre els beneficis i la gratitud (CeG I.29 i III.2) // Bacus i Hèrcules ajuden Curial a regenerar-se moralment i tornar a l'estudi ( $C e G$ III.79).

5. MAcrobi. Autor citat explícitament en la novel la i d'obres accessibles a la biblioteca napolitana del rei Alfons. * Commentarium in «Somnium Scipionis», I, vIII, 7-8. Les virtuts del neoplatònic Plotí, en el sermó de l'eremita Sanglier (CeG III.10), amb la intermediació, documentada per Juan F. Mesa, de Pietro Alighieri (Comentum, 3a red., Purg. I, vv. 28-69). * Commentarium, II, III, 1-7 // Saturnals, I, xIx, 15: Apol lo i la lira de set cordes, temperant l'harmonia celestial i «musical dolçor» de les esferes o planetes (CeG III.0, III.27 i III.29). * Commentarium, II, I, 9: El «brogit» de molts ferrers ferint sobre moltes encluses (CeG II.47). * ibid., I, Ix, 1-3: Consell de Melchior a Curial: «que torns en tu mateix e regoneix-te bé» (CeG II.144). * ibid., I, III, 4-6: Repertori de somnis i visions, que inspiren les del Curial. * ibid., I, v, 15-17: Simbolisme especial dels múltiples de 7 i del guarisme 8.

6. Boeci. De fàcil accés a la cort. * Consolatio Philosophiae, IV, prosa VII, par. 15: Fortuna «no pot noure al savi diligent com a l'ignorant negligent» (CeG III.80). Segons Melchior, la providència de Déu dispensa bona i mala fortuna ( $C e G$ III.2). 
7. Pseudo-Dionís Areopagita. * De ecclesiastica bierarchia: Curial visita Atenes i l'Estudi (Acadèmia platònica) on s'aprén la «sciència de conèxer Déu» (CeG III.24), la teosofia. Per mediació d'Hug de Sant Víctor, Exposició sobre la «Jerarquia celest» de Dionís l'Areopagita, obra posseïda per D’Àvalos, que la manà a relligar en format sumptuós.

8. Quintilià. Autor present a can D’Àvalos i en la biblioteca reial. * Institutiones oratoriae, I, vIII, 2: La Retòrica, amb una partitura en la mà, que la relaciona amb el cant (CeG III.79). * ibid., II, x, 4: «Bo és lo poetar, mas contra veritat escriure, no m par sie loon» (CeG III.34).

9. Ptolemeu. * Tetrabiblos, IV, 10: Importància de les edats múltiples de 7, com els 21 anys de Curial (CeG II.0). D’Àvalos i el seu nebot i pupil, Pietro de Guevara, posseïen les obres de Ptolemeu. Com també l'humanista Giovanni Pontano. * ibid., XX i XXII: Caracterització i influxos de la deessa-planeta Venus (CeG II.0).

10. Plini el VelL. * Naturalis historia, IX, LI, 74: Cicle vital de la «cullereta o ranapeix de pantà o marjal» (CeG III.18). Un dels llibres predilectes de Ferran d'Aragó, futur rei de Nàpols.

11. Fulgenci. Autor citat explícitament. * Mythologiae, I, 15: Faula al legoritzada de les Muses (CeG III.0), a través de la consulta de Boccaccio (Genealogie deorum gentilium), Pietro Alighieri (Comentum de Dante), Giovanni del Virgilio (Allegoriae, o exposició de l'Eneida) i un comento dantesc de Da Imola en versió montferratesa (vid. supra). * ibid., I, 12: La quadriga solar d'Apol lo-Febus: «Titan, Etheus, Lampaus, Philogeus» (CeG 101 i 129). Algun mitògraf desconegut, que explicaria la tergiversació ortogràfica dels noms.

III. Historiadors i tractats de «disciplina militar»

1. Xenofont. * Hieró, o Sobre la tirania, I, 29-30: Els turcs són tirans, perquè combaten de cos, però no amb l'ànima ( $C e G$ III.91). D'Àvalos posseí una còpia de l'opuscle en versió llatina de Leonardo Bruni (De tyranno), conservada a Harvard. * Memorabilia (Records de Sòcrates), II, I, 21-22: Faula de Pròdic de Queos. Curial, seguidor de l'Hèrcules davant la cruilla: evita el vici i escull la virtut ( $C e G$ III.79). Possible coneixença del mite a través de Ciceró (De officiis, I, XxxII, 118-XxxIII, 119), o de Basili el Gran, $A d$ adolescentes. Aquest darrer opuscle, en versió llatina de Bruni, figura en un còdex davalià conservat a Harvard.

2. CÈSAR: Commentarii de bello civili, III, LXXXIx, 4-5, i XCIv, 3. Obra citada implícitament: «la [battaglia] de Júlio [Cesaro] e Pompeyo» (CeG III.91). Estratègia de Curial contra els turcs, quan «estoja» 8.000 homes «freschs» ( $C e G$ III.91), com proposen Lola Badia i Jaume Torró. Decembrio dedicà tot el Corpus Caesarianum, traduït al toscà, al duc de Milà, tret d'aquest llibre, dedicat a D’Àvalos (1438), amb el títol Le bataglie de Cesaro et Pompeo. Enyego fou l'introductor de l'obra de Cèsar a Castella, el 1440 . 
3. SAL Lusti. Autor citat explícitament. * Bellum Iugurtinum, LXIV, 10: «Comune malum nobilitas est superbia» (CeG III.10), amb Pietro Alighieri (Comentum, 3a red., Purg. XI, 67-69) d'intermediari, com proposa Juan F. Mesa. * De coniuratione Catilinae, VIII, 1-4. Obra citada explícitament: «la [conjuració] de Cathilina» (CeG III.91). Lloança de la virtut dels coetanis (coaevorum virtus) en comparança amb la dels antics (CeG III.0). D’Àvalos en posseí un exemplar, titulat In Catilinam.

4. Valeri MÀxim. * Facta et dicta memorabilia, III, II, 14: Sobre Cató: «Virtut és la fortalesa del meu cor» (Ce G III.55). I comparant el valor de Càmar amb el de Pòrcia, en autolesionar-se (CeG III.48). * ibid., V, I, 2: Remissió proverbial a l'exemple moral de Pisístrat d'Atenes (CeG III.81). Consultat en la versió catalana d'Antoni Canals, assequible a la cort, així com també el Valeri original en llatí.

5. Titus Livi. Autor citat explícitament, molt estimat pel rei Alfons i present, en diversos còdexs, en la biblioteca de D’Àvalos. * Dècades, XXII, 40-52 i XXX, 29-35: Al lusió a les batalles de Cannes i Zama (CeG III.91). * ibid., III, 48: Càmar evoca la tràgica mort de Virgínia (CeG III.55).

6. Plutarc. * Vides paral Vleles. Vida de Sertori. Possible inspiració del nom de «Pompeu» per al cavall de Pere el Gran (CeG II.38). D’Àvalos posseí les Vidas semblantes (versió aragonesa, coservada a París) i una versió llatina (1444-1445) de Florència (conservada allí, també). * ibid. Vides de Filopèmen i Titus, II, 3; Vides de Pirros i Mari, XV i XXXIII; Vides de Cimó i Lucul le, XXXVI; Moralia (cap. Com traure avantatge dels enemics). Nova ètica cavalleresca: «traure avantatge», com féu Aquil les quan vencé Hèctor, és una virtut (CeG III.34). * ibid. Vida de Ròmul, XXI, 2-3: Broma pseudoetimològica sobre la fetillera Carmentis (< carens mentis), en CeG III.15. * Moralia. Septem sapientium convivium, II, 13, 156c-d: «Venus és dea de concòrdia e de pau, e convida les gents a amar-se e voler-se bé» (CeG III.22). Aquest opuscle inspirà els Convivia Mediolanensia de Filelfo, en els quals introdueix entre els tertulians Aenicus D’Àvalos i el seu germà menor, Alfons. * Moralia, De musica, XIV, 78: L’origen de la música, relacionat amb Apol lo i les Muses, com en CeG III.0. En el I Convivium de Filelfo (Milà, 1443), D’Àvalos, excel lent músic, disserta sobre aquesta qüestió. * De virtutibus mulierum, V // Apogtemes: Curial, emporeguit, volent amagar-se davall les faldes de sa mare ( $C e G$ III.24). També apareix l'anècdota en les Històries filípiques, I, 6, de Justí, que segueix Plutarc. D’Àvalos encarregà el volgarizzamento del De virtutibus mulierum a Alamanno Rinuccini. El còdex es conserva a Olomuc (Txèquia).

7. Vegeci. * Epitome rei militaris, III, IX, 3: El savi cavaller és aquell qui venç procurant evitar cautelosament el perill (CeG III.62). * ibid., III, xxI: El consell d'Escipió de facilitar la fugida a l'enemic vençut (CeG III.92). També apareix en Frontí, Stratagemata, IV, vII, 16. D’Àvalos posseïa, com a bon capità de cavalleria, un bell exemplar del Vegeci.

8. Frontí. Accessible a la cort. Stratagemata, I, Ix, 11-12: La importància de «simular» davant els soldats el favor dels déus (o de Sant Jordi, en el cas de Curial, CeG III.91).

9. TeOfRAST. Historia plantarum, III, XVIII, 11-12: Smilax ('sarsaparrella' en Ovidi, Metam. IV, 283) esdevé Míloe (flor de teix), un hàpax potser degut a a Teofrast, on el teix és milos. D’Àvalos, interessat en medicina i veterinària, posseïa el manual de Teofrast, en versió llatina de Teodoro Gaza: una primícia humanística. 
IV. Homer, Virgili, Ovidi i altres literats antics

1. Homer. Autor citat explícitament. * Ilíada: Broma erudita sobre la Ilíada com un Achileydos o llibre dedicat a Aquil les (CeG III.26), l'heroi predilecte de l'autor del Curial. Protagonisme d'Homer en el judici del Parnàs. D'Àvalos manà al Pisanello que li fera una medalla amb un simbòlic escut d'Aquil les (1449), basat en la Ilias latina. El mateix Enyego divulgà l'obra i la figura d'Homer a Castella $(1440,1446) . *$ ibid., IX, 440-443: Aquil les caracteritzat com «molt ben parlant... e gran emprenedor» ( $C e G$ III.31), com un diplomàtic; com en l'ambaixada d'Aquil les en la versió llatina del cant IX, de Leonardo Bruni. Fernando de Guevara (a precs del seu germà, el diplomàtic D’Àvalos) lliuraria a Santillana la traducció de Bruni (1446). * ibid., VI, 466-470: Com Astiànax, Curial sent por d'Hèctor i busca refugi en una dona (CeG III.24). A partir de la traducció de Lorenzo Valla, com suggereix Jaume Torró. A petició del rei Alfons, Valla, molt amic de D’Àvalos, traduí la Ilíada pels anys 1441-1445. D’aquesta versió podrien venir altres referències: XX, 283-285: Aquil les, «prompte a respondre» (CeG III.31); XX, 196-197: Aquil les, «alegre» (bilarem) i «amich de son amich» (CeG III.31).

2. Teognis. Poemes, vv. 173-181: La fugida de la pobresa (CeG I.1), requisit per a trobar la virtut. Filelfo també fa sàtira de la pobresa (Satyrae, IX, 9) per a demanar a D’Àvalos que intercedisca davant el rei i puga cobrar.

3. Isop. Autor traduit per Lorenzo Valla a la cort de Nàpols. * La faula de la pell de l'ós: El «venator intrepidus» que fa front a l'ós amb els gossos és recreat en la pugna de Curial contra Sanglier $(\mathrm{Ce} G$ II.101), en paral lel a una traducció llatina, que inspirà una medalla alfonsina del Pisanello llaurada el 1449 sota supervisió de D’Àvalos (vid. supra).

4. Píndar. * Odes. Pítica I, vv. 130-194: Exaltació del triomf de Curial amb el lema «Ans anvie que pitié» (CeG III.99). Hi havia versió llatina (1429-1434) encarregada per Filelfo, gran amic de D’Àvalos. Recomanada per Manetti, amic també de D’Àvalos, a Alfons el Magnànim, rei de les Dues Sicílies, pel fet d'estar dedicada a un antic sobirà grec de Sicília. * Odes. Pítica II, v. 72: Admonició moral: «yo t prech, Curial, que torns e tu mateix» (CeG II.144). Però també en Agustí, De vera religione, XXXIX, 72.

5. Llucià. * Diàlegs dels déus: Diàlegs en clau de sàtira llucianesca entre déus, en CeG III.23 et passim. D’Àvalos participà dels cercles humanístics milanesos del 1430 on Llucià era un autor apreciat.

6. Filòstrat. * Vida d'Apol loni de Tiana, IV, 11 i 15: El Curial, en la visió del Parnàs (CeG III.24 i III.33), sembla parodiar l'ascens d'Apol loni al sepulcre d'Aquil les, on se li apareix aquest, en forma d'espectre gegant, i conversa amb ell. Filelfo, gran amic de D’Àvalos, descobrí a Constantinoble la Vida, la portà a Itàlia el 1427 i circulà en cenacles humanístics.

7. Virgili. Autor i obra citats explícitament. D’Àvalos fou estudiós de l'Eneida i posseïdor de diversos Virgilis. Ensenyà sa filla Constança a cantar, sonant l'arpa, els amors de Dido (testimoni 
de Paolo Giovio). Filelfo, en els Convivia Mediolanensia (I, ca. 1443) denomina Enyego/Inico com Aenicus (<Aeneas), li atorga epítet de «loquens virgilianus» i el presenta glossant algun passatge del poema èpic amb amics. A la cort de Nàpols era una de les lectures predilectes de l'hora del llibre. * Eneida, I i IV; V, 1-7, i VI, 450-476: La Dido enamorada d'Enees (CeG III.34). Superació d'aquest amor per Càmar i Curial (CeG III.37 al III.67). Curial ajuda Càmar a interpretar una Eneida traduïda i glossada (CeG III.68). * ibid., I, 50-64, 127, 658-660; II, 123; III, 37, 134-136; IV, 76-83, 101, 125-127, 283, 447, 449, 463-464, 548, 552, 569-570, 595-596, 646, 693, 696-697; V, 55 i 787; VI, 268-269, 279-281, 403 et passim, 450-460, 672-679, 734 i 749-750: Discurs tràgic de la suïcida Càmar, farcit d'intertextualitats virgilianes (CeG III.66). Se'n retroben en altres punts de l'episodi africà (CeG III.51, III.55 i III.59) i en altres passatges (CeG II.76, III.13). Alguna citació connecta amb glosses d'Enric de Villena (núm. 235); d'altres, amb versos de Dante (Inf. V, 61-62; Parad. VIII, 7-9). Coneix també el que expliquen Petrarca i Boccaccio sobre Dido.

8. Ovidi. Autor citat explícitament, així com les seues famoses «transformacions» ( $C e G$ III.0). D'Àvalos, en la col lecció de clàssics heretada per sa filla Constança, tenia diversos Ovidis. * Metamorphoseon, I, vv. 468-471: Les sagetes d'or i de plom de Cupido (CeG I.24, III.16 i III.95). Potser a través de Boccaccio (Geneal. deor. IX, 4) o Pietro Alighieri (Comentum, Parad. VIII, 1-12). * ibid. I, vv. 649-650: Io, inscrivint amb la pota el seu nom en les arenes de Líbia (CeG III.15). * ibid. I, 720-721: La «insoferible resplandor» dels cent ulls d’Argus (CeG III.95). * ibid. II, 667-669: «Girona, filla de Giron [Ocírroe]..., convertida en jumenta» ( $C e G$ III.15); en Ovidi, «simulantis equam». Potser, per causa d'un Ovidi moralitzat milanés (inèdit fins el 1790), on «Chirona» (per confusió amb l'acusatiu grec de Chiron) esdevé «jumenta». D'Àvalos residí a la cort de Milà, amb algunes interrupcions, del 1435 al 1447. * ibid. II, 768-783: Inspira la caracterització grotesca i esgarrifosa de l'Enveja en CeG III.99. * ibid. III, 253-315: Sèmele concep Bacus de Júpiter (CeG III.15). Potser seguint Boccaccio (Geneal. deor. II, 64). * ibid. III, 333-335: Juno arranca els ulls a Tirèsies (CeG III.15). * ibid. IV, 145-146: Els tràgics amors de Píram i Tisbe presagien el fracàs de la relació Làquesis-Curial (CeG I.26). * ibid. IV, 283: Crocos i Esmílax, convertits en flors (CeG III.15). * ibid. VII, 391-393: «Poble de Corinto..., mudat en bolets» (CeG III.15). Mite associat còmicament al de Crocos i Esmílax. L'autor es riu d'una crítica de la filosofia antiga per Lactanci (Divinae Institutiones, V, IV, 3). En Ovidi, Corint és «Ėfire». Saber que aquesta Ėfire era Corint és cosa d'humanistes... D'Àvalos posseïa còpia de l'Institutiones adversus gentiles de Lactanci. * ibid. IV, 366: L'abraçada de la nimfa Sàlmacis a Hermafrodit («utque sub aequoribus deprensum polypus hostem»), parodiada en la de Càmar a Curial amb «braços de polp» (CeG III.59). * ibid. XI, 116-117 i 125: El mite de «Prondes»/Dànae (IV, 607-611), però amb remissió al de Mides («or colat o regalą» < aurum fuitare, CeG III.15). Dànae esdevé «Prondes» (< Pronoe), per influència d'un passatge de Diodor Sícul (Bibliotheca Historica, IV, LXVIII, 5). Decembrio, acollit per D’Àvalos a Nàpols, posseïa un còdex amb l'obra de Diodor, per la qual s’interessà el rei Alfons. * ibid. IV, 673-675: Record («una ymatge de marbre torní», CeG II.69) de Perseu enamorant-se de la bellesa escultòrica d'Andròmeda. * ibid.. V, 294-317, 663-678: Faula de les Muses «colents Helicona» (< «Helicona colentes») i les Pièrides (CeG III.0). Potser a través de Pietro Alighieri (Comentum, 1 red., Purg. XXIX, 37-42). Vegeu també 
més amunt, on tractem de Fulgenci. * ibid. V, 341-408: Ceres «stuprada per... Jovis» (CeG III.15). Dependència de Boccaccio, Geneal. deor. VIII, 4. * ibid. VI, 101-145: El mite d'Aragne, evocat en CeG III.19. * ibid. VI, 103-104: Europa i Júpiter (CeG III.15), amb dependència de Boccaccio, Geneal. deor. II, 62. * ibid. VI, 109: Leda, «filla de Theseu» (sic), transformada en cigne (CeG III.15). Fer Leda filla de Teseu és un error pres del Marcià Capel la (De nuptiis...) glossat per Iohannes Scotus (glossa 488,1). * ibid. VI, 110-111: Mite d'Antíope, dita Nicteida en Ovidi (CeG III.15). * ibid. VI, 112: Júpiter egendra Hèrcules en Alcmena, seguint Boccaccio (Geneal. deor. XII, 28). * ibid. VI, 113: Mite d'Egina i Júpiter: dita «Asopida» en Ovidi, però «filla de Ysop» [sic], el de les faules que traduïa Valla per a educar l'infant Ferran (CeG III.15), a manera de broma hilarant. * ibid. VI, 114: Mnemòsine, deturpada com «Menòsia» en CeG III.15, jau amb Júpiter i engendra les Muses. Trobem aquest hàpax Menosia en algun Ovidi moralitzat del nord d’Itàlia, on residí D’Àvalos. * ibid. VI, 114: Prosèrpina Deoida, com l'anomena també Ovidi. Diu Boccaccio que Prosèrpina Deoida no jagué amb son pare, Júpiter; que fou una Prosèrpina homònima. L'autor confuta, en context paròdic, Boccaccio, i certifica un brutal incest entre pare i presumpta filla. * ibid. VI, 424-674: Evocació del mite de Procne (CeG III.55). La transcripció de Prognes, Ítim, Filomena, upega..., remeten a algun Ovidi moralitzat nord-italià, i, en algun cas, a Boccaccio (Geneal. deor. IX, 8). * ibid. VII, 367-370: El mite de Ctèsil la, amb alguna tergiversació paròdica (CeG III.15). * ibid. VII, 386-387: Menefró, transformat en «bèstia fera», encara que Ovidi sols el compara amb una bèstia (CeG III.15). La forma Menofron prové, segurament d'algun Ovidi moralitzat. * ibid. VII, 396397: Evocació de Medea, filla del rei «Oetes», la qual «matà sos propris fills» (CeG III.55). «Oetes» remet a Boccaccio (Geneal. deor. IV, 12). * ibid. VII, 518-660: Egina i els mirmidons (CeG III.15): destrucció d'Egina per Juno (vv. 523-524), amb tergiversació de noms (*Aigina > Argiva; *Eginia $>$ Ogie [n]ta) i al lusió a les formigues (v. 622 i ss.). Possible deformació de noms a partir d'algun Ovidi moralitzat medieval. * ibid. VII, 796-804: El mite de Cèfal i Procris inspira l'aparició de Venus a la Güelfa (CeG III.95): «radio terram illustrante» esdevé «un raig il lustrant la terra». * ibid. VIII, 130-137: Història de Pasífae, Minos, Dèdal i el Minotaure (CeG III.55). Depén de la consulta de Boccaccio, Geneal. deor. IV, 10 i del Trattato della superbia (caps. 5-6) de Jacopo Pasavanti, molt corrent i divulgat a Itàlia. * ibid. VIII, 203-204: L’advertència de Dèdal a Ícar i el consell de Curial al seu herald: «No puges tant que te n'endenys, ne t baxes tant que n valles menys» (CeG II.24). * ibid. X, 155-161: Evocació del mite de Ganímedes, però parodiant còmicament la glossa 147 a l'Eneida d'Enric de Villena (CeG III.15), conegut d'infantesa i mestre d'erudició d'Enyego. * ibid. X, 500-502: El mite de les llàgrimes de Mirra (CeG III.55). * ibid. XIII, 600-622: L'autor confon deliberadament el Mèmnon ovidià (correctament identificat en un altre passatge de l'obra) amb el rei Minos de Creta, el del laberint. Fa, a més, de les Memnònides uns «auzells» que fan versos $(\mathrm{Ce} G$ III.15). Remet a la identificació que feien Estrabó i altres del Memnònium (laberint egipci) amb el laberint del mite de la Creta minoica. Els ocells poetes són d'un satíric Llucià (Incredulus, 33). Aquest detall erudit no s'explica sense els contactes de D'Àvalos amb Filelfo i altres humanistes estudiosos (dècades del 1420-1440) del redescobert Estrabó; a més de traductors de sàtires de Llucià. * ibid. XIII, 568-569: El mite d'Hècuba, convertida en gos ( $C e G$ III.10). Depenent de la consulta de Da 
Imola, Comentum, Inf. XXX, vv. 13-21. * ibid. XV, 500-501: El mite de Fedra i Hipòlit (CeG III.55), «no volent corrompre lo llit paternal» (< «patrium temerare cubile»). * Heroides, I, 30. Penèlope a Ulisses: Càmar s'enamora com Dido i besa Curial «penjat... dels labis» (CeG III.59). Citat i comentat per Valla (Epístola a Alfons el Magnànim, Nàpols, 1444). * Amores, I, xxx, vv. 45-46: Júpiter «doblà... en dues nits» la nit durant la qual concebé Hèrcules d'Alcmena (CeG III.15).

9. Horaci. * Sàtires. Autor citat com Oràcio, en italià i parafrasejat Dante, Inf. IV, 89-90. Es detecta algun possible influx d'aquest autor, però no hi ha constància de cap intertextualitat rellevant.

10. Persi. * Satyrae. Prologus, vv. 1-13 (Choliambi): El sàtir, sense ser poeta, com Curial (CeG III.2435), passa una nit somniant al Parnàs, i es desperta coronat com un «poeta». Afecta també el proemi III. Obra accessible en els cercles humanistes de Milà i Nàpols. A Nàpols (Bibl. Naz. XIII G 33) se'n conserva còpia en un còdex nord-italià del 1441.

11. Properci. * Elegies, III, iII, vv. 1-52: Visita onírica al Parnàs (CeG III.24-35), amb «les nou donzelles» i Cal líope d’interlocutora ( $C e G$ III.27). D’Àvalos posseïa un còdex amb les obres poètiques de Catul i Properci. * ibid., III, II, 9-10: Bacus i Apol lo, en el doble cim del Panàs ( $C e G$ III.34). * ibid., III, v, 1: Venus, «dea... de pau» (CeG III.22): «Pacis Amor deus est».

12. LuCÀ. Autor popular a Itàlia i a la Península Ibèrica. Citat com Lucano, parafrasejat Dante, Inf. IV, 89-90, i situat entre els grans poetes antics (CeG III.28). * Farsàlia, V, vv. 505-677: Referència satírica al mite clàssic -i fraresc- d'un Amicles que va cantant per les places sense témer l'ira règia (CeG III.9). Connexió temàtica amb Dante (Parad. XI, 67-69), Boccaccio (Geneal. deor. XIV, 4; Midas) i Juvenal (Satyra X, v. 22). * ibid, VI, vv. 688-690 i V, 395-396: El «bubó» que denuncia «mals avuyrs».

13. Estaci. Autor clàssic napolità. Filelfo presenta Enyego d’Àvalos (I Convivium, Milà, 1443) dissertant sobre Cadme, fundador de Tebes, ciutat murada present en el Curiali en la medalla que el Pisanello dedica a D’Àvalos (1449). * Tebaida, «de la qual tant scriví Staci en lo seu Thebaydos»: Interés per Tebes, ciutat que «primerament murà Cadmo» (CeG III.34). * ibid., XII, vv. 420-446 (especialment, vv. 429-432). Citació còmica sobre una visita de Curial als «sepulcres de Etíocles e Pol licines, cruels germans» (CeG III.34). Reapareixen en CeG III.55. * Silvarum libri, V, I, vv. 135150: El lligam de parentiu establit entre Fortuna i la «iniqua» Enveja en el Curial (II.122, II.125, III.23, III.37, III.94 i III.100).

14. Juvenal. * Sàtira X, vv. 355-366: Defenestració satírica de la Fortuna, degradada a no res per l'home virtuós: un leitmotiv del Curial. Filelfo, «il Giovennale del Quattrocento», fou amic i protegit de D'Àvalos i dedicà les seues Sàtires al rei Alfons. * Sàtira XIII, vv. 19-21: Els «sacri libelli» o llibres de «reverenda letradura», gràcies els quals l’home esdevé virtuós i supera els avatars de la Fortuna.

15. Marcial. * Epigrames, III, LXv, 2 i IX, XxXVIII, 5: Explica l'estranya associació entre la ciutat de Corint i el mite de Crocos i Smílax de CeG III.15, per una confusió del safrà (crocos) de Còric (Corycio) amb Cory [n]tio. D’Àvalos tingué de preceptor i bibliotecari, al seu palau de Nàpols, Angelo 
Decembrio, que posseïa un còdex antic dels Epigrames. Fou també molt amic de Beccadelli, un dels èmuls renaixentistes de Marcial.

16. Apuleu. D’Àvalos posseí un còdex titulat De asino aureo. * Asinus aureus, IV, 31, 1: Els «encenalls» de foc de la torxa de Cupido, quan s'apareix Venus a la Güelfa ( $C e G$ III.95), com proposa Sònia Gros. * ibid., IV, 29-30: La Venus Urània o platònica «col locada en lo cel» (CeG I.22, III.16, III.17, III.23, III.95). * ibid., passim: Caracterització de Corint com un poble «molt luxuriós» (CeG III.15). Segons Apuleu, les matrones de dita ciutat practicaven la zoofília. * ibid., V, II, 9: Les germanes envejoses («sorores egregiae») del mite d'Eros i Psique ressonen en les «egrègies sorel les» del proemi III del Curial, pel possible record d'algun volgarizzamento en toscà. Aquesta faula, arromançada, fou popular a les corts principesques dels Sforza, Este, Gonzaga i Aragó (Nàpols).

17. LuCRECI. * De rerum natura, III, vv. 11-13: Els poetes clàssics «dauren» els «actes d'argent» i els eternitzen ( $C e G$ III.0): «aurea dicta, aurea perpetua semper dignissima vita».

\section{Conclusió}

Com s'observa, al darrere de Curial e Güelfa hi havia tota una voluntat d'exhibició culturalista; de voler demostrar l'autor, aquell intel ligent i accidental anònim, tot allò que havia aprés en els cenacles humanístics d'Itàlia. Ell fou un home educat encara de l'edat mitjana, en un món de cavallers i de nostàlgia cortesa pels trobadors, però la seua manera d'aproximar-se als clàssics era ja molt italiana, que és com dir renaixentista. Segurament es tractava d'algú que, com el cavaller lector Curial el llombard, «entre los grans philòsofs, poetes e oradors, veig que és tengut en gran stima [...], e tracta tan reverencialment los libres, que tots quan lo conexen ho han a gran maravella» (Curial e Güelfa, 11. II, cap. 116, ed. Ferrando 2007: 247). Devia ser algú com un gran camarlenc lector i poliglota, i amic de filòsofs, poetes i oradors: Enyego d'Àvalos, el perfecte curial del Quattrocento. 


\section{Bibliografia}

Badia, L. (1988 [1985]) «La segona visió mitològica de Curial i notes per a una interpretació de l'anònim català del segle XV», dins Beltran, V. (ed.) Actas del I Congreso de la Asociación Hispánica de Literatura Medieval (Santiago de Compostela, 2 al 6 de diciembre de 1985), Sant Jaume de Galícia, pp. 157-176.

Badia, L. \& Torró, J. (eds.) (2011) Curial e Güelfa, Barcelona, Quaderns Crema.

De Vivo, R. (1996) «La biblioteca di Costanza d'Avalos», Annali. Sezione Romanza, 38/2, pp. $287-$ 302.

Ferrando, A. (2007) «Introducció», dins Ídem (ed.) Curiale Güelfa, Tolosa de Llenguadoc, Anacharsis, pp. 5-35.

Mesa Sanz, J. F., (2012) «Las fuentes del latín del Curial e Güelfa», dins Ferrando, A. (ed.), Estudis lingüistics i culturals sobre "Curial e Güelfa», novel la cavalleresca anònima del segle XV en llengua catalana, Amsterdam, John Benjamins, vol. 1, pp. 387-428.

Soler, A. (2017a) «Enyego d’Àvalos, autor de Curial e Güelfa?», Estudis Romànics, 39, pp. 137-165.

Soler, A. (2017b) La cort napolitana d'Alfons el Magnànim: el context de «Curial e Güelfa», València / Barcelona, Publicacions de la Universitat de València / Institució Alfons el Magnànim / Institut d'Estudis Catalans, 2017, 3 vol.

Soler, A. (2018), Enyego d'Àvalos i l'autoria del «Curial», València / Barcelona, Institució Alfons el Magnànim / Institut d'Estudis Catalans / Publicacions de la Universitat de València. 